
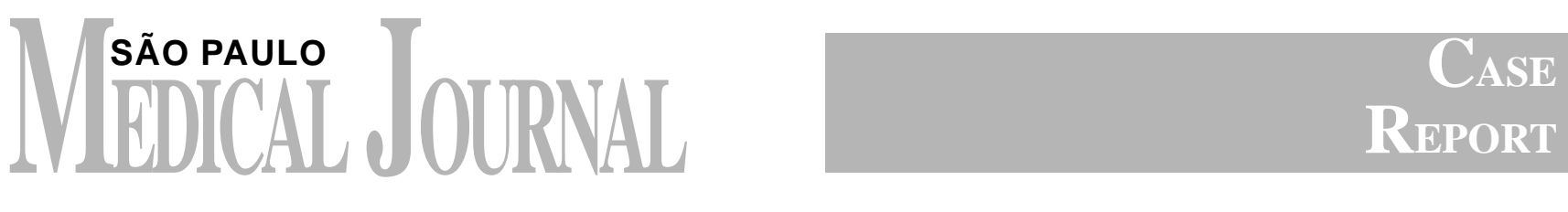

Júlio César Teixeira, José Roberto Salina, Luiz Carlos Teixeira, Liliana Aparecida Lucci De Angelo Andrade

\title{
Primary melanoma of the uterine cervix figo stage III B
}

\author{
Department of Gynecology, Division of Oncology and Department of Pathology \\ Universidade de Campinas (UNICAMP). Campinas, Brazil
}

\begin{abstract}
The primary malignant melanoma of the uterine cervix is rare, usually diagnosed at an advanced stage and with poor prognosis. The diagnosis is made through histological evaluation and confirmed by special staining procedures. Radical surgery has been used and advocated. However in its advanced stages chemotherapy, immunotherapy or radiotherapy can be employed. A case of a patient with malignant melanoma of the uterine cervix, Stage $\mathrm{Illb}$, is presented in addition to a clinical and pathological discussion.
\end{abstract}

Uniterms: Melanoma. Cervix. Neoplasma. Diagnosis. Pathology.

\section{INTRODUCTION}

$\mathrm{D}$ espite the increase in incidence of skin melanoma in recent decades, it is rare in the lower genital tract, being approximately $3 \%$ to $7 \%$ of all cases. The majority these tumors arise on the vulva and then on the vagina ${ }^{1,2}$ Primary melanoma of the cervix is rare, with about 35 cases described in the literature. ${ }^{3}$ No predominance of any age group has been observed and these patients have ranged in age from 26 to 74 years. ${ }^{2,3}$

The clinical history usually includes abnormal genital bleeding, and physical examination reveals an exophytic cervical mass, pigmented or otherwise, usually involving the vaginal fornices in more than $50 \%$ of the cases at the time of diagnosis. ${ }^{2,4}$ The malignant cells with their melanic

\footnotetext{
Address for correspondence:

Júlio César Teixeira

Rua Joaquim Novaes, 35

Campinas/SP - Brasil - CEP 13015-140
}

pigment can be detected via the cervical smear. Diagnosis is confirmed by the histological examination and immunohistochemical staining. ${ }^{1,3}$ Management of such cases has included radical surgery, irradiation and immuno or chemotherapy, although even with good therapeutic results, the survival time is short. ${ }^{1,2}$

A case of primary malignant melanoma of the cervix, Stage IIIb, is presented with its diagnosis and treatment.

\section{CASE REPORT}

A 65-year-old white woman with a 2-month history of vaginal bleeding and pelvic pain, began treatment in our care in July 1994. On physical examination an exophytic cervical mass was observed, $6 \mathrm{~cm}$ in diameter, ulcerated with darkened borders, involving the vaginal fornices and parametrial invasion up to the pelvic wall. The pelvic ultrasonography showed a uterine cervix of $6.4 \times 4.5 \mathrm{~cm}$, having heterogeneous texture. Computed tomography of the abdomen and pelvis demonstrated a large-sized pelvic tumor. The proctosigmoidoscopy, 
cystoscopy, chest radiograph, fundoscopic exam and computed tomography of the cranium were normal.

Biopsy of the lesion was performed and the pathological diagnosis was undifferentiated neoplasm composed of spindle-shaped cells containing mitotically active dark pleomorphic nuclei containing prominent nucleoli (Figs. 1 and 2). The mitotic count was more than 10 mitoses per 10 high power fields. Cytoplasmic pigment was not observed and immunohistochemical staining was done to distinguish it from other neoplasms, like spindle cell carcinoma and sarcoma. Immunohistochemical stains showed strong reactivity for the S-100 protein and for the melanoma-specific antibody HMB-45, and absence of immunoreactivity for epithelial antigens. A vaginal biopsy showed pigmented malignant neoplasia, with in situ melanoma and focuses of superficial invasion, whose histological diagnosis was pigmented malignant melanoma of the lentiginous type (Fig. 3).

With a diagnosis of locally advanced primary malignant melanoma of the uterine cervix, and also because the patient presented Hansen's disease in the reactional phase and reduced kidney function, external pelvic irradiation with megavoltage was started. After the application of $3420 \mathrm{cGy}$, an absence of response was observed and the patient then abandoned the treatment. Through phone contact we were informed of the death of the patient 6 months after the diagnosis.

\section{DISCUSSION}

Melanoma of the cervix is a rare and aggressive neoplasia. About $60 \%$ of the cases already had clinical evidence of tumor beyond the cervix at the time of diagnosis $^{2,3}$ and the 5-year survival rate decreases from $40 \%$ for Stage I to $14 \%$ for other stages. ${ }^{4}$ Due to the rarity of the primary melanoma of the cervix, the possibility of metastatic neoplasia coming from a melanoma at a different site, or which may have been treated several years before, must always be investigated. In some cases it is impossible to locate the primary site of the disease. The case described did not have a history of any other melanoma, the largest tumoral volume being in the uterine cervix and spreading to the vagina. Moreover, the lentiginous pigmented malignant neoplasia of the vagina, with its in situ melanoma and focus of superficial invasion, is conclusive as to its primary origin in the lower genital tract. According to the literature, malignant melanoma of the cervix has a poor prognosis and is frequently associated with vaginal

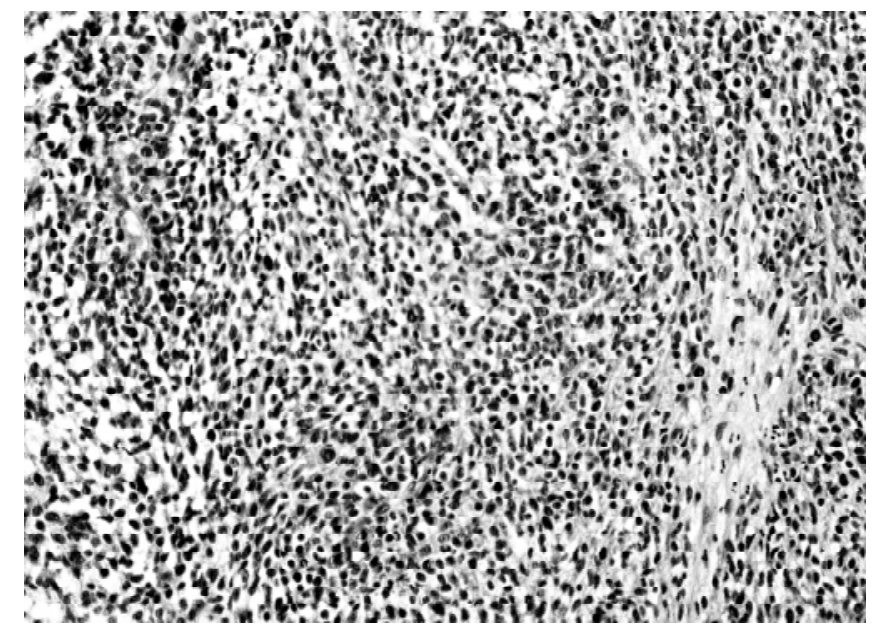

Figure 1 - The cervical biopsy showed a solid proliferation of undifferentiated malignant neoplasm with spindle-shaped cells. Hematoxylin and eosin, x50.

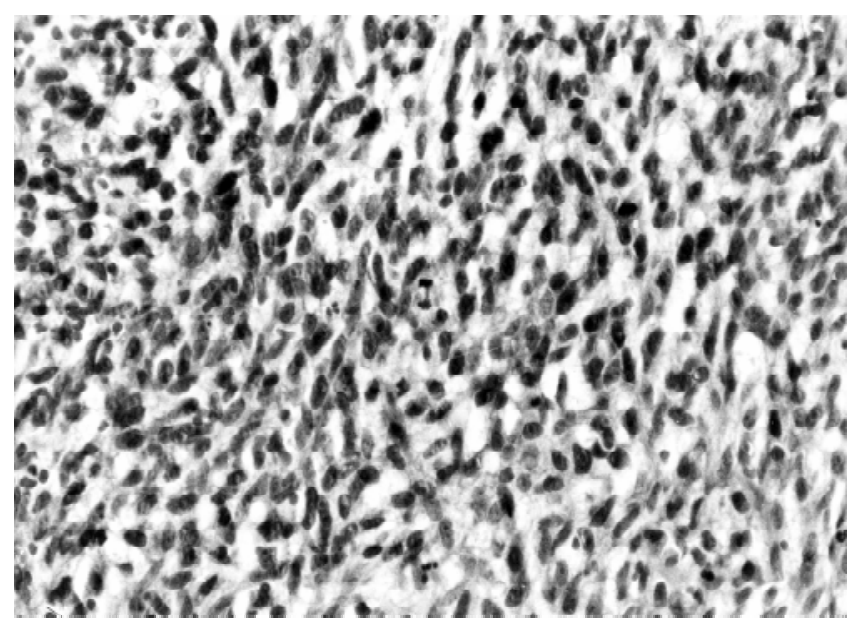

Figure 2 - At higher power, the cervical biopsy demonstrates malignant cells with pleomorphic nuclei, and prominent nucleoli and frequent mitosis. Hematoxylin and eosin, x100.

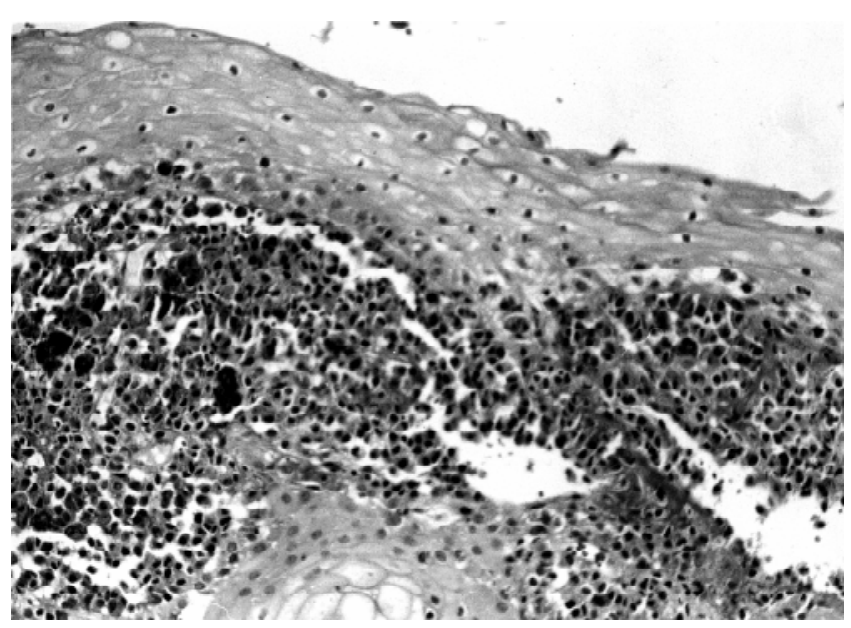

Figure 3 - Vaginal biopsy showed cells pigmented by melanoma, superficially invasive into the stroma. Hematoxylin and eosin, x50. 
disease, whether from direct extension of the cervix or due to metastasis. ${ }^{3,4}$

There is no defined treatment. According to the spreading pattern of the tumor, the patient could be treated with radical hysterectomy, pelvic lymphadenectomy and total colpectomy. Despite the low radiation sensitivity of melanomas, radiotherapy can be indicated when surgery is not complete or not possible. However, the results are limited, even when associated with immunotherapy or chemotherapy. ${ }^{1,2}$ Survival is usually short due to metastasis, independently of the local disease control. ${ }^{1,2,4}$

Thus, only by early detection via preventive gynecological examination and periodic cervical smears can the disease be detected in its early stages, which may contribute to an increase in survival time. In the present case the patient had the disease in an advanced stage and the proposed radiotherapy was only palliative and incomplete, resulting in short survival.

\section{REFERENCES}

1. Kristiansen SB, Anderson R, Cohen DM. Primary malignant melanoma of the cervix and review of the literature. Gynecol Oncol 1992;47:398-403.

2. Morrow CP, DiSaia PJ. Malignant melanoma of the female genitalia: a clinical analysis. Obstet Gynecol Surv 1976;31:233-71.

3. Clement PB, Young RH. Tumors and tumorlike lesions of the uterine corpus and cervix. New York: Churchill Livingstone 1993:393-5.

4. Mordel C, Mor-Yoset S, Ben-Baruch N, Anteby SO. Malignant melanoma of the uterine cervix: case report and review of the literature. Gynecol Oncol 1989;32:375-80.

\section{RESUMO}

O melanoma primário do colo uterino é raro, geralmente diagnosticado em estádio avançado e com pobre prognóstico. 0 diagnóstico é feito através da avaliação histológica e confirmado por colorações especiais. A cirurgia radical tem sido preconizada. Contudo, nos estádios avançados, a quimioterapia, imunoterapia ou radioterapia podem ser empregadas. O caso de uma paciente com melanoma malígno do colo uterino estádio Illb é apresentado juntamente com sua discussão clínica e patológica. 